Joseph Yelepuo Wegru

\title{
THE DAGAABA-FRAFRA JOKING RELATIONSHIP
}

This is a copy of the article from printed version of electronic journal

\section{Folklore Vol. 14}

ISSN 1406-0957

Editors Mare Kõiva \& Andres Kuperjanov

Published by the Folk Belief and Media Group of ELM

\section{JPolklore}

\section{Electronic Journal of Folklore}

Electronic version ISSN 1406-0949 is available from http://haldjas.folklore.ee/folklore

It's free but do give us credit when you cite!

(C) Folk Belief and Media Group of ELM, Andres Kuperjanov

\section{Tartu 2000}




\section{THE DAGAABA-FRAFRA JOKING RELATIONSHIP}

\section{Joseph Yelepuo Wegru}

\section{INTRODUCTION}

The present article concerns inter-ethnic humour and its development between the Dagaaba and Gurune (or Frafra) tribes in Ghana. This is but one aspect/dimension of the total socio-cultural richness of these people, which needs to be researched and recorded for succeeding generations. For instance, Kropp-Dakubu (1988) deplores the unsatisfactory state of knowledge about the origins of the various languages of northern Ghana and the small number of people qualified to write about them. Kropp-Dakubu's lament about the state of northern Ghanaian languages can be applied, to some extent, to our present discussion. None of the works on the life of these two tribes addresses the present topic. It is also important to note that until well into the 1960 s, when Dagaaba intellectuals entered the scene, little new historical research was being carried out on the Black Volta ${ }^{1}$ region, either in Ghana or in Burkina Faso. The attention of earlier scholars was concentrated on only pre-colonial states such as Dagomba, Gonja, Wa and Mossi. The so-called 'stateless societies' remained marginal to the interest of most historians (Lentz 1994). This neglected area of academic research includes the two tribes of our present discussion.

The crucial matter of this article is based on a legend, narrated by Anthony Atarebore ${ }^{2}$ during an interview ${ }^{3}$ conducted by the writer himself, in the quest for an explanation to the Dagaaba-Frafra joking relationship in Ghana. However, it is essential to trace this development in the context of history, mythology, folklore, culture and traditions of these peoples. Aware of the limited and debatable documentary evidence available on the origins of these peoples, the article does not claim to be a final authority on the subject. Research on oral tradition regularly points out that migration stories and genealogies cannot be taken at face value. We can only attain certain levels of plausibility (Lentz 1994). 
The first comprehensive ethnographic survey of the western Sudan, which includes the two tribes under our discussion, was made by Delafosse at the instigation of Clozel, Governor of the Colonie du Haut-Sénégal-Niger, within some twelve years of the final occupation of the area by the French (Goody 1967). Following this pioneering work, many other scholars, including Jack Goody, have done further extensive work on the Dagaaba at different times. Greenberg, Westermann, Wilks, Labouret, Rattray, Hamilton and Cardinall, Lentz, Somé, to mention a few, have done some general anthropological and historical work on the people of northern Ghana. St. John-Parsons D. has also compiled Legends of Northern Ghana. However, there is very little exclusive literature on the Frafra people in the Upper East Region of Ghana.

\section{THE ORIGIN OF THE GURUNE AND THE DAGAABA}

The Dagaaba is a predominantly agricultural tribe of a little over one million, living in the northwestern part of Ghana called the Upper-West Region, and in southwestern Burkina Faso. Although they speak a continuum of several dialects (Dagaare, Waala, Birifor), Dagaare appears to be the umbrella language for the dialects. The major towns of the Dagaaba in Ghana are Wa, Lawra, Jirapa, Babile, Nandom, Hamile, Nadawli, Kaleo, Daffiama, and Tuna. However, there are also many Dagaaba communities in Accra, Kumasi, Cape Coast, and most major towns and villages throughout the country.

Until recently the Dagaaba were subsistence farmers and hunters (Goody 1962). Farming is so central to the economy of Dagao that more and more people migrate southwards in search of better lands. It is fashionable for adolescent Dagaaba to move down south in the dry season to farm for money and the success of their first trip has become more or less a yardstick for measuring their growth to adulthood and their ability to live independently and raise a family.

The Gurune or Frafra ${ }^{4}$ are also predominantly agricultural people in the north-eastern part of Ghana called the Upper East Region. Major Gurune towns include Bolgatanga, Bongo, Zuarengu, Somburungu, and they also live in surrounding villages. Today, the Gurune can be found in many major towns and villages all around Ghana including Accra, Kumasi, Tamale, Sunyani and Cape Coast. They 
are also highly mobile, often travelling south to look for work during the dry season. There are also some Gurune-speaking people (the Nankani) in Navrongo District, which is generally a Kasemspeaking area. Native Gurune are also found in Burkina Faso, in the Nahouri province, Eastern part of Tiébélé and in the region of Pô.

Gurune, Nankani, Booni, Talni, and Nab't together with some others are considered the major dialects of the Frafra people. However, Nab't and Talni could also be considered dialects of Mampruli; Mampruli, Kusaal, and Dagaare are in turn considered to be sister languages to Gurune. There are obvious linguistic similarities among these and the other languages of the Mabia language group (Bodomo 1994; St. John-Parsons 1960).

\section{PLAYMATES}

It is common knowledge in Ghana that the Dagaaba and the Gurune have an admirably cordial relationship. They can joke and tease each other in the public without either taking undue offence as they have mutual understanding as Mabia, or playmates. ${ }^{5}$ Either party's age, sex, religion, educational or social status does not influence this cordial relationship; being born in either tribe is the sufficient prerequisite. Active participation in the jokes is, however, not compulsory. Although there are some who neither initiate nor participate in the jokes, neither do they prevent others from joking.

The concept of playmates is not confined to the Gurune and Dagaaba tribes in Ghana. Several other tribes in the country share this concept and exercise it among themselves. For instance, the Kasena and the Sisaala are playmates. Playmates can also be members of the same tribe (Goody 1967). For instance, the Zage and the Naayile are two Dagaaba clans who are playmates. Similar groups can be found also among other tribes. Playmates are often in the position of an intermediary resolving conflicts and restoring peace among community members.

However, the focus of this article is not on the concept of playmates as a whole (a field that has been intensively studied in anthropol- 
ogy), but on the Gurune-Dagaaba playmate relationship, which recently has gained both national and international attention. Fraternity between these two tribes is a positive phenomenon amidst the growing number of ethnic and tribal conflicts that plague the African continent today. Having a relationship of playmates is healthy for ethnic groups, diffusing tensions in potentially dangerous situations.

\section{THE ORIGIN OF THE RELATIONSHIP}

The origin of the Gurune-Dagaaba relationship is as yet undetermined. Little is known as to its origin. People accept joking as a common practice between the two tribes, their general concern is but to enjoy the jokes and live in harmony. However, fascinating stories and legends are told in connection with its origin. Many ethnic groups or sub-groups in northern Ghana have legendary history telling how their ancestors came from Mamprusi or Dagomba lands, but it is not clear whether these narratives reflect migration of whole peoples or the arrival of chiefly families to rule over previously chiefless peoples (Kropp-Dakubu 1988).

According to a legend narrated by Anthony Atarebore ${ }^{6}$, the Frafra and the Dagaaba were both linked with the Dagomba. This Dagomba connection re-echoes Hébert's legend about the first Dagara, an orphan who was accused of witchcraft and expelled by the Dagomba chief. The orphan accordingly fled towards the Black Volta and stayed near Babile, across the river. However, both legends do not account for the relationship with other ethnic groups ${ }^{7}$, which are shown to belong to a common Mabia ancestry (Bodomo 1994).

Bodomo (1994) rejects the hypothesis put forward by Tuurey (1982) and Hébert (1976) that the Dagaaba are a splinter group from either the Mossi or the Dagomba (or both), who moved into the present area and assimilated (or got assimilated by) earlier settlers and/or new arrivals. As stated above, the work instead suggests all these belong to an earlier and larger parent ethnolinguistic group - the Mabia that broke up into many separate tribes probably due to hardships encountered during migration. Even though there is not any known legend connected to this hypothesis, Kropp-Dakubu (1988) seems to suggest how this might have happened. 
If migration separates different groups or speakers of a language, for instance, by a big river or mountain frontier, then the speech of the group will change independently of the changes in the other. Thus we find different varieties of a single language - what we call dialects. If the dialects continue to be separated and to differ more and more from each other then eventually the speakers of each will no longer understand the speakers of the other, and we will have two distinct languages derived from one original tongue. Such languages would be said to be 'related' and the analogy of human kinship is used to describe them as 'descended' from the same 'parent' or 'ancestor' language. If the two descendant languages themselves split into dialects and then into further descendant languages then we can talk of 'sub-families' and of closer or more remote relationships. In this way we consider that all the languages which we call Gur which includes the Dagaaba and the Frafra may be the result of many, many centuries of change and migration and splitting up of what was originally one ancestor language.

We will elaborate further Atarebore's legend that a long time ago, Dagomba, Gurune and Dagao were brothers, or rather cousins. They lived somewhere in Southern Africa among the Bantus. From Southern Africa, they began to migrate northwards through Zimbabwe, Uganda, Rwanda and Kenya. Then, turning westward, they moved to Sierra Leone, Northern Nigeria, and finally to Ghana. Historians differ in their opinion as regards to the nature and scale of these movements. For instance, Lentz (1994) rejects the hypothesis put forward by Eyre-Smith's ${ }^{8}$ that the history of northern Ghana, indeed of the whole West African savannah, seemed to consist of 'constant' movements of people as a result of slave-raiding, internecine warfare, etc., whole sections of a tribe or family breaking away and migrating to a new territory. Instead, Carola Lentz suggests that migration took place in small-scale distances and in small groups.

In general, there are some cultural similarities between the Dagaaba, the Dagomba and the Gurune, and some peoples living in the countries mentioned. These include wedding customs, bringing up children, respect for the elderly, etc. Similar food and clothing are also fair indicators of common origin, in addition to other social and 
cultural similarities, which also seem to indicate the validity of the legend. This is purely the writer's own assumption.

Phonetic similarities in some person names in these countries also suggest the plausibility of the legend. For instance, the name 'Abongo' is common both among the Gurune in Ghana and among some of the peoples in Kenya. Another name, 'Bayuo' or 'Beyuo' is also common among the Dagaaba in Ghana as well as among some of the peoples in Sierra Leone. Staniland (1975) suggests that the Dagomba were pagans of Hausa ${ }^{9}$ origin, possibly from Zamfara, one of the old Hausa 'Banza Bokwo' states located in northern Nigeria. Atarebore's legend suggests that from here, the family began to move westward and finally reached Ghana.

Upon arriving in Ghana, the family settled in Damongo, south of Tamale, exercising trade in hides and skin. They agreed to travel in turns to Upper Volta [current Burkina Faso], to buy goods to sell in Ghana. Dagomba was the first to go. He bought goods and came back. ${ }^{10}$ Next Dagao went, but he did not return. He got married and settled in Burkina Faso. He became both the chief $[\mathrm{Naa}]$ and the landlord [Tendaana ${ }^{11}$, or Tengansob] there. ${ }^{12}$

After a long time waiting in vain for the return of Dagao, Dagomba decided to send Gurune to look for him. In Burkina Faso he found the brother happily married and doing very well. He was the owner of vast farmlands and numerous animals. He was so well established that he could afford to marry fifty or more wives. Having many wives was a symbol of status in society. It turned out that the visitor like the host was not to return. Dagao kept him from going back. ${ }^{13}$

Consequently, Gurune settled with his brother and the two worked together in Burkina Faso. They were both prosperous and hard working. Gurune got married and the two families continued to live together in harmony.

Dagao decided to share his authority with Gurune. He gave Gurune the title of the chief, but retained the title of landowner. According to tradition, the office of the landowner is more important than that of the chief.

A time came when they wanted to perform a thanksgiving sacrifice to God. Dagao, who was the Tendaana, consulted with the ancestors as to the best sacrifice. A dog was chosen. The sacrifice was to be held at dawn on a chosen day. 
As it would be difficult to kill a dog at dawn, they decided to kill it the previous evening. Only the head and entrails of the dog were needed, so they took and hid these parts. But when everybody was sleeping, the oldest son of Gurune stole the sacrificial meat. He was eating it when the oldest son of Dagao found him. Together they ate all the meat, but decided to hang the skull on the family shrine.

In the morning when the elders gathered for sacrificing, Dagao went to fetch the meat, but the meat had disappeared. The whole house was searched and the compound swept to no avail. They found only dry bones hanging over the shrine. The poor elders were drowned in fear and wondered what to do next.

Then the youngest son of Gurune came forth as an eyewitness. He had seen his elder brother and cousin eating the meat. But Dagao could not accept that his son was a thief and put the blame on Gurune's son. This annoyed Gurune so much that he decided to move out of the house and go his way together with his family. Upon leaving he threatened to go east and prevent the sun from rising. Fearing what his brother might do, Dagao decided to move his family west so that he could prevent the sun from setting.

And this is why the Gurune is found in the east, the Dagomba in the south and the Dagaaba in the west of Northern Ghana.

A legend may not provide factual information, yet it entertains and stimulates critical thinking. However, it provides a possible explanation of Dagaaba-Frafra jokes involving 'dog head' as in the following two stories. The main subject of the story usually depends on the narrator. The Dagao tells the story against the Frafra and vice versa.

A Fraframan was riding his motor bike without wearing his crash helmet. Instead, he hung the helmet on the handlebars of the machine. On his way, the police stopped him to ask why he was not wearing the crash helmet but rather preferred to have it hanging on the handlebars of the machine. "You should always wear a crash helmet to protect your head", said the policeman. "Exactly, that is what I have done to the head. I am protecting it with the crash helmet", replied the Fraframan. Surprised at the response, the guard grabbed the helmet from the handlebars and a dog's head fell out. 
A Fraframan was cooking dog meat in his house when his Dagao friend visited. Meanwhile, the Fraframan had taken out, from the pot, some of the meat he was cooking to taste when he heard the friend's voice in the courtyard. He was greedy and did not want to share with his friend. So, he quickly removed his hat, put the hot piece of meat into it and put it back on his head. He then met the friend at the gate with the intention of not allowing him into the house. He wanted to receive the friend casually and dismiss him quickly. But the friend was in great talking mood and kept talking for a long time. The Fraframan then became very uncomfortable and began to twist his head sideways so as to ease the pain. In the process, the dog meat fell out of the hat.

The legend also describes the roles of the Tendaana and the Naa among the Dagaaba, Dagomba and Gurune. The distinctive functions of the Tendaana and the Naa among these tribes are respectively spiritual and political.

The influence of the Hausa language on Dagaare is another example to the point. The word barika for 'thank you' in Dagaare is, in actual fact, a Hausa word, not to mention the derivation of tuo zaafi and fitoo (pito) which are, respectively, the staple food and drink of the native people of Northern Ghana. However, KroppDakubu (1988) suggests this could have happened due to interactions through trade and commence.

\section{GROWTH AND DEVELOPMENT OF THE RELATIONSHIP}

Participation in the jokes has several benefits. They appear spontaneously regardless of place, occasion, or circumstance. The jokes are always similar in content and context, be it at the market place, the pito bar or the funeral house. Joking usually involves one-toone informal play and takes place whenever and wherever members of the two tribes meet. In fact, knowing the other person to be a Frafra or Dagao gives a feeling of brotherhood. One can go ahead with play even if it be the first time they meet.

Benefit to brotherhood seems to be the main purpose of the jokes between the two tribes. Through jokes, social and moral concepts 
like love, peace, understanding, hospitality, generosity, concern for others, to mention but a few, are developed. Members of the two tribes have always supported each other in both good and bad times. They attend and take active part in each other's celebrations - weddings, funerals and other important holidays.

The jokes also help to lower initial communication barriers, establish trust and make it easier to approach each other. Consequently, sharing is facilitated and it takes place in the atmosphere of peace, trust and mutual understanding. Moreover, the general public also enjoys the joking. Sometimes 'foreigners' want to participate in the jokes.

As mentioned before, the Gurune and Dagaaba are very mobile. They travel to the southern part of the country in search for employment during the dry season after harvest. This common pattern makes the tribes allies in a way and probably also contributes to keeping the relationship between them alive. ${ }^{14}$

Such joking is similarly popular among members of the two tribes who are either Catholic priests or followers of the Navrongo-Bolgatanga diocese. During their annual Christmas and Easter picnics, a dog is usually killed and the head carried around in jubilation to show their unity and solidarity.

Up to this point, one may be tempted to conclude that the GuruneDagaaba relationship is all roses and no thorns. Unfortunately, there have been cases of conflict and misunderstanding due to the jokes. Sometimes jokes are focused on teasing, and not edifying or brotherly communication. For instance, calling somebody 'an ugly doghead eater' is an insult rather than a joke. There was also an occasion in Bolgatanga where pieces of packing foam were mixed with scrambled eggs and served to some Dagaaba for breakfast. Extensive joking can create animosity between the best of friends. Therefore, participants have to be sensitive to the feelings of others.

\section{CONCLUSION}

Although there are some problems, it seems that both tribes are willing to continue the relationship; they want to know its origins 
and they want their children to keep it up. One way to strengthen this relationship would be via common cultural and sports events. Inclusion of cross-cultural differences in school curriculum and exchange projects of both teachers and pupils of different regions could also be organised. Such cultural and social activities have the potential of reducing prejudices among both tribes. Invitation to and participation in each other's annual festivals are also examples. Joking has also encouraged inter-tribal marrying.

Jokes should exclude elements affecting the dignity and welfare of any group. The joking relationship has the potential of resolving conflicts. Participants need to treasure and nurture it to let it mature.

This article has attempted to find origins of the Dagaaba-Frafra jokes, a modest contribution to the on-going debate about the historiography of 'stateless' peoples in the northern Ghana. It has also sought to stimulate the reader to further research in the subject: one can ask the elders, or search libraries, and when he writes down what he has learned, the rich oral traditions will be turned into well-written history.

Members of the two ethnic groups need to consciously work at reforming the relationship so as to make it more acceptable, enjoyable and dignified. They should continue to work together and organise more joint cultural and educational activities at all the levels to include their confreres in the neighbouring countries.

\section{Comments}

${ }^{1}$ The Black Volta is the name of the western tributary of the Volta River in Ghana

${ }^{2} \mathrm{Mr}$. Anthony Atarebore is a teacher in the Bolgatanga Education District, Ghana.

${ }^{3}$ This interview took place on 20 March 1995.

${ }^{4}$ It may be interesting to acknowledge how the name 'Frafra' became the accepted name for both the people and the language of the area under discussion. The name 'Frafra' originates from the first missionaries' interactions with the natives during the early 1900s. Every time the missionaries visited a compound and were leaving, the people always, 'Frafra' (mean- 
ing 'Thank you' or 'Well done'). Therefore the missionaries started calling them 'the Frafra people'. The natives, on their part accepted the 'new' name and also began using it themselves. The term Frafra gradually came into general use.

${ }^{5}$ A playmate is hereby understood in the context of the definition in Collins English Dictionary (1979 page 1124): 'a friend or a partner in play or recreation'.

${ }^{6}$ Cf. note 2.

${ }^{7}$ These other groups are the Birifo, the Mamprusi, the Nankani, the Kussasi, the Waala, and the Mossi.

${ }^{8}$ Eyre-Smith was a colonial historical author.

9 'Hausa' refers to the people and the language of northern Nigeria and southern Niger. This language spread to other parts of the West African sub-region mainly through trade.

10 This suggests the etymological origin of the Dagomba. Da in Dagaare means 'buy' and gbang means 'leather'. Literally, therefore, Dagomba means 'the one who goes to buy leather'.

${ }^{11}$ The tendaana is the fetish-priest whose duties are connected with the land. He is a different person from the chief, naa.

${ }^{12}$ Etymologically Da means 'buy' and gao means 'to lie down' or 'to sleep'. Therefore, Dagao literally means 'the one who goes to buy and sleeps'.

${ }^{13}$ This act of prevention somehow suggests the etymological meaning of the name Gurune. Literally, it means 'the one who is prevented'.

${ }^{14}$ Another significant development worth mentioning is the joint sports activities of the Frafra and the Dagaaba living in Accra. These friendly games have become recently very popular, catching the interest of the general public. The games foster unity, peace and love among the members of the two tribes in and around Accra.

\section{Refences}

Bodomo, A. B. 1994 . Language, Culture, and History in Northern Ghana: An Introduction to the Mabia Linguistic Group. Nordic Journal of African Studies, 3 (2). Finland. 
Bodomo, A. B. Dagaare Language and Culture. Navrongo and Lawra Home Page (http://users.erols.com/johnston/lawra-language-culture.htm)

Goody, J. 1967. The social organisation of the LoWiili. London: Oxford University Press for the International African Institute.

Grimes F. B. (Ed.) 1996. Ethnologue: Languages of the World. SIL International.

Hébert, J., et al. 1975. Esquisse d'une Monographie Historique du Pays Dagara. Diebougou, Burkina Faso: Unpublished.

Kropp-Dakubu, M. E. (Ed.) 1988. The languages of Ghana. London: Kegan Paul International for the International African Institute.

Lentz, C. 1994. A Dagara Rebellion against Dagomba Rule? Contested Stories of Origin in North-Western Ghana. Journal of African History, 35, pp. 457-492.

St. John-Parsons, D. 1958. Legends of Northern Ghana. London: Longmans.

St. John-Parsons, D. 1960. More Legends of Northern Ghana. London: Longmans.

Staniland, M. 1975. The Lions of Dagbon: Political Change in Northern Ghana. London: Cambridge University Press.

Tuurey, G. 1987. Introduction to the Mole-speaking Community. Washington: Catholic Press. 